\title{
Kesesuaian Lahan dan Keberlanjutan Pengelolaan Kawasan Wisata Alam Pantai Panjang di Kota Bengkulu
}

\author{
Ellya Revolina ${ }^{1}$, Aceng Hidayat ${ }^{2}$, Sambas Basuni ${ }^{3}$, dan Widiatmaka ${ }^{4}$
}

1 Program Studi Ilmu Pengelolaan Sumberdaya Alam dan Lingkungan, Sekolah Pascasarjana Institut Pertanian Bogor, Bogor, Indonesia; e-mail: revolina_ellya@yahoo.com

2 Departemen Ekonomi Sumberdaya Alam dan Lingkungan Fakultas Ekonomi dan Manajemen Institut Pertanian Bogor, Bogor, Indonesia

${ }^{3}$ Departemen Konservasi Sumberdaya Hutan dan Ekowisata Fakultas Kehutanan Institut Pertanian Bogor, Bogor, Indonesia

4 Departemen Ilmu Tanah dan Sumberdaya Lahan Fakultas Pertanian Institut Pertanian Bogor, Bogor, Indonesia

\begin{abstract}
ABSTRAK
Kawasan wisata alam Pantai Panjang di Kota Bengkulu merupakan alternatif wisata alam yang sering dikunjungi wisatawan, namun tidak dikelola dengan maksimal sehingga menimbulkan permasalahan baik lingkungan, sosial, ekonomi maupun kelembagaan. Aspek kelembagaan dan kesesuaian lahan menjadi isu utama dalam pengelolaan kawasan ini sehingga diperlukan riset yang dapat dijadikan alternatif pertimbangan dalam pengambilan kebijakan pemerintah setempat. Penelitian ini bertujuan untuk mengetahui kesesuaian lahan dan status keberlanjutan pengelolaan kawasan wisata alam Pantai Panjang di Kota Bengkulu. Metode yang digunakan dalam penelitian ini adalah deskriptif kualitatif untuk menganalisis status kesesuaian lahan kawasan wisata alam Pantai Panjang. Metode penilaian cepat untuk pesisir atau Rapid Appraisal for Coastal (Rap-Coast) digunakan untuk mengetahui status keberlanjutan pengelolaan kawasan wisata alam Pantai Panjang. Hasil penelitian menunjukkan bahwa kawasan wisata Pantai Panjang sangat sesuai (kategori S1) untuk aktivitas wisata, dan memiliki nilai $89.286 \%$ pada skala nilai 80 - 100\%, tetapi status keberlanjutan pengelolaan kawasan wisata alam Pantai Panjang termasuk kurang berkelanjutan pada dimensi ekonomi (MDS 47.59), sosial (MDS 42.74), kelembagaan (MDS 40.79), dan termasuk cukup berkelanjutan pada dimensi ekologi (MDS 52.02).
\end{abstract}

Kata kunci: kawasan wisata, keberlanjutan, kesesuaian lahan, pantai panjang, wisata alam

\begin{abstract}
The natural tourism area of Pantai Panjang in the Bengkulu city is an alternative natural tourism which is often visited by tourists but not managed properly. Institutional aspects and land suitability are the main issues in the management of this area. Research is needed that can be used as an alternative consideration in local government policy making. This study aims to determine the land suitability and the sustainability status of the management of Pantai Panjang natural tourism area in Bengkulu City. The method used in this research is descriptive qualitative to analyze the land suitability status of the Pantai Panjang natural tourism area. The Rapid Appraisal for Coastal (Rap-Coast) method is used to determine the sustainability status of the management of the Pantai Panjang natural tourism area. The results showed that the Pantai Panjang tourism area was very suitable (category S1) for tourism activities, and had a value of $89.286 \%$ on a scale of $80-100 \%$, but the sustainability status of the management of the Pantai Panjang natural tourism area was less sustainable on the economic dimension (MDS 47.59), social (MDS 42.74), institutional (MDS 40.79), and including quite sustainable in the ecological dimension (MDS 52.02).
\end{abstract}

Keywords: land suitability, natural tourism, pantai panjang, sustainability, tourism area

Citation: Revolina, E., Hidayat, A., Basuni, S., dan Widiatmaka. (2020). Kesesuaian Lahan dan Keberlanjutan Pengelolaan Kawasan Wisata Alam Pantai Panjang di Kota Bengkulu. Jurnal Ilmu Lingkungan, 18(2), 261-271, doi:10.14710/jil.18.2.261-271

\section{Pendahuluan}

Pantai Panjang adalah salah satu kawasan wisata alam yang berada di Kota Bengkulu, memiliki letak strategis dengan jarak hanya sekitar $2 \mathrm{~km}$ dari pusat kota dan berada di jalan utama Kota Bengkulu. Pantai dengan ciri khas berpasir putih dengan ruang terbuka hijau bervegetasi alami berupa cemara yang terdapat di sepanjang pantai. Letak yang strategis dan keunikan vegetasi pantai menjadi salah satu kekuatan yang dimiliki oleh kawasan ini sehingga selalu ramai dikunjungi wisatawan setiap harinya. Berdasarkan PP nomor 50 tahun 2011 tentang Rencana Induk Pengembangan Pariwisata Nasional, Pantai Panjang dan sekitarnya ditetapkan sebagai kawasan 
Revolina, E., Hidayat, A., Basuni, S., dan Widiatmaka. (2020). Kesesuaian Lahan dan Keberlanjutan Pengelolaan Kawasan Wisata Alam Pantai Panjang di Kota Bengkulu. Jurnal IImu Lingkungan, 18(2), 261-271, doi:10.14710/jil.18.2.261-271

pengembangan pariwisata nasional (KPPN). Lalu melalui Perda nomor 02 tahun 2012 kawasan Pantai Panjang ditetapkan sebagai kawasan strategis kota. Kemudian melalui Perda nomor 14 tahun 2012 tentang Rencana Tata Ruang Wilayah (RTRW) Kota Bengkulu tahun 2012-2032, Pantai Panjang disebut sebagai salah satu kawasan strategis wisata alam.

Merujuk pada berbagai peraturan di atas, Pantai Panjang memiliki peran yang penting sebagai kawasan yang ditetapkan bagi pengembangan kepariwisataan, ekonomi, kesehatan dan pelestarian alam. Namun pengembangan potensi yang dimiliki belum dapat dikembangkan secara maksimal. Beberapa fenomena yang tampak saat ini di antaranya, pengelolaan sampah yang tidak tertangani dengan baik, jarak pandang ke laut terhalang oleh bangunan di sepanjang jalur kawasan, belum adanya jalur-jalur koneksi yang jelas di dalam kawasan, tidak ada pedestrian, tidak ada pintu masuk/entrance yang jelas, fasilitas parkir tidak layak, kawasan belum memiliki fasilitas penunjang pariwisata yang memadai (toilet tidak berfungsi, sarana ibadah tidak tersedia, pusat informasi tempat pedagang belum tersedia), saluran drainase tidak terkoneksi sehingga tidak berfungsi, ketersediaan jaringan listrik belum ada, dan belum tersedianya ruang-ruang untuk atraksi wisata. Munculnya fenomena tersebut disebabkan oleh pengelolaan dan tata kelola yang belum tepat, seperti pengelolaan tidak melibatkan pemangku kepentingan yang lain, pengelolaan masih parsial belum holistik, serta belum terpadunya kebijakan antara Pemerintah Provinsi Bengkulu dengan Pemerintah Kota Bengkulu. Fenomena yang terjadi di kawasan wisata alam pantai panjang secara umum disebabkan oleh faktor kelembagaan, meliputi ketidakjelasan lembaga pengelola dan aturan main yang belum mencerminkan keberlanjutan pengelolaan kawasan wisata alam Pantai Panjang.

Peran pemerintah sebagai pemegang kendali dan decision maker pembangunan sangat dibutuhkan untuk mengelola dan mengembangkan potensi kawasan (Angelina \& Evelina, 2014), termasuk kawasan wisata pantai. Disamping itu pemerintah tetap harus menjamin kealamiahannya secara berkelanjutan sehingga menjadi daya tarik tersendiri bagi para pengunjung. Wisata pantai merupakan kegiatan wisata yang mengutamakan sumberdaya pantai dan budaya masyarakat pantai seperti rekreasi, olahraga, menikmati pemandangan dan iklim (Yulianda, 2019). Pemahaman berbagai karakteristik kawasan diantaranya kesesuaian lahan, menjadi modal utama untuk melakukan pengelolaan secara berkelanjutan. Pengelolaan kawasan wisata alam Pantai Panjang secara berkelanjutan menjadi sangat penting dalam rangka menjaga peletarian alam kawasan (Laksono \& Mussadun, 2014).

Tujuan penelitian ini adalah untuk mengetahui kesesuaian lahan dan status keberlanjutan pengelolaan kawasan wisata alam Pantai Panjang di Kota Bengkulu. Pemahaman karakteristik kesesuaian lahan dan status keberlanjutan pengelolaan kawasan wisata alam Pantai Panjang sangat penting dilakukan, sebagai dasar perencanaan kebijakan di masa yang akan datang.

\section{Metode Penelitian \\ 2.1 Sumber Data}

Data untuk kajian kesesuaian lahan dalam penelitian ini menggunakan data sekunder. Sedangkan data untuk analisis keberlanjutan menggunakan data primer dan data sekunder. Data primer seperti parameter biofisik diperoleh dan dikumpulkan langsung melalui observasi lapang. Sedangkan untuk beberapa parameter ekonomi, sosial dan kelembagaan dilakukan dengan metode wawancara mendalam (depth interview) terhadap 1 orang perwakilan yang ditentukan secara purposive, dari beberapa pihak terkait yang merupakan informan kunci (key person), yaitu Dinas Pariwisata, Badan Perencanaan Pembangunan Daerah, BKSDA, Dinas Kelautan dan Perikanan, Dinas Kehutanan dan Lingkungan Hidup, Dinas Tata Ruang dan Pemukiman, Lembaga Masyarakat Desa, tokoh masyarakat, wisatawan, dan masyarakat sekitar kawasan wisata. Adapun pengumpulan data sekunder dilakukan dengan cara studi literatur dari berbagai dokumen di beberapa instansi terkait dan hasil-hasil penelitian sebelumnya.

\subsection{Analisis Data}

Analisis kesesuaian lahan yang digunakan dalam penelitian ini yaitu mengacu pada rumus dan kriteria kesesuaian lahan untuk wisata pantai menurut Yulianda (2019), yaitu sebagai berikut :

$$
\boldsymbol{I} \boldsymbol{K} \boldsymbol{W}=\sum_{i=1}^{n}(B i x S i)
$$

$\begin{array}{lll}\text { Keterangan : } & \text { IKW: IKW } \geq 2,5 & \text { : Sangat sesuai } \\ & 2,0 \leq \mathrm{IKW}<2,5 \quad \text { : Sesuai } \\ & 1 \leq \mathrm{IKW}<2,0 \quad \text { : Tidak sesuai } \\ & \text { IKW }<1 & \text { : Sangat tidak sesuai }\end{array}$

Analisis keberlanjutan menggunakan Multi Dimensional Scaling (MDS) melalui teknik ordinasi Rap-Coast (Rapid Apraisal for Coast) yang merupakan teknik statistik untuk melakukan transformasi multimedia menjadi dimensi yang lebih sederhana (Fauzi dan Anna 2002). Rap-Coast yang dimodifikasi dari RAPFISH (Rapid Apraisal for Fisheries) merupakan alat untuk mengevaluasi keberlanjutan kawasan pantai secara multidimensi. Secara ringkas tahapan analisis keberlanjutan/MDS dengan RapCoast disajikan pada Gambar 1 (Fauzi 2019).

\section{Hasil dan Pembahasan}

\subsection{Analisis Kesesuaian Lahan Kawasan Wisata Alam Pantai Panjang}

Penilaian parameter kesesuaian lahan wisata alam Pantai Panjang di Kota Bengkulu mengacu pada matriks kesesuaian lahan untuk wisata pantai kategori rekreasi pantai. Terdiri atas 10 parameter yaitu, parameter kedalaman perairan, tipe pantai, lebar pantai, material dasar, kecepatan arus, 
kecerahan perairan, kemiringan pantai, penutupan lahan pantai, biota berbahaya, dan ketersediaan air tawar Yulianda (2019). Hasil pengukuran parameter kesesuaian lahan untuk wisata alam Pantai Panjang dilengkapi juga dengan hasil penelitian Apriliansyah et al. (2018) seperti dalam Tabel 1.

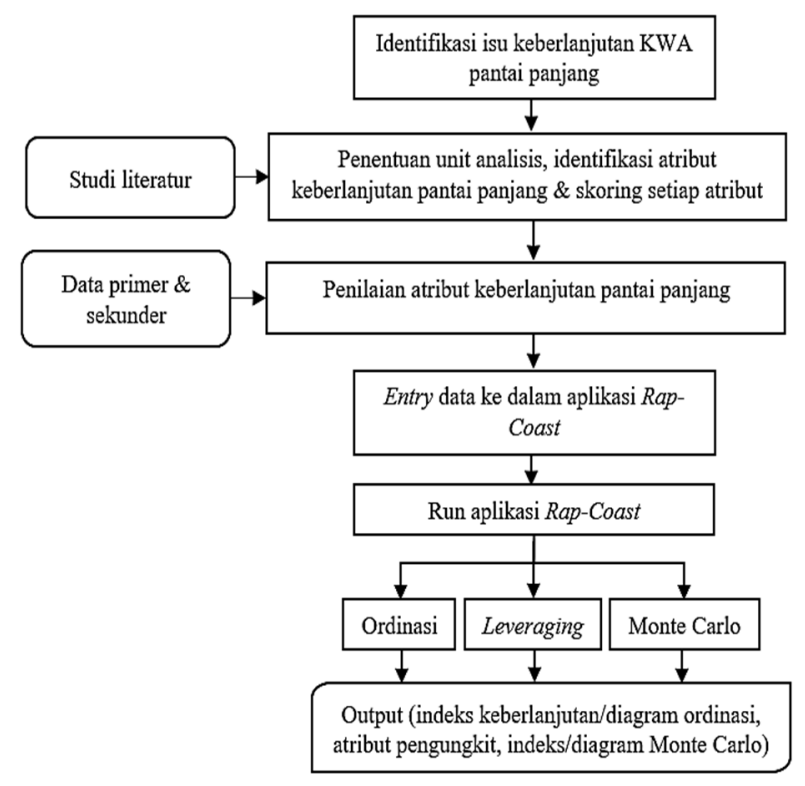

Gambar 1 Tahapan analisis keberlanjutan (MDS) dengan Rap-Coast

\subsubsection{Kedalaman perairan}

Kedalaman perairan menjadi faktor penting dalam penentuan suatu kawasan untuk dijadikan sebuah kawasan wisata pantai karena berhubungan dengan kegiatan mandi dan berenang. Selain itu, juga berhubungan dengan keselamatan wisatawan. Kedalaman perairan pantai panjang kurang dari 1 meter sehingga sangat baik untuk kegiatan wisata. Menurut Yusthisar et al. (2012), pada kedalaman perairan yang tidak terlalu dalam dapat dilakukan kegiatan wisata berenang. Kegiatan berenang tidak dapat dilakukan atau akan menjadi resiko yang tinggi jika kedalaman lebih dari $5 \mathrm{~m}$.

\subsubsection{Tipe pantai}

Tipe pantai di kawasan Pantai Panjang termasuk kategori berpasir. Hardjowigeno dan Widiatmaka (2007) menyebutkan bahwa tipe pantai yang sangat sesuai untuk kegiatan wisata pantai berdasarkan jenis substrat/sedimen adalah pantai berpasir. Di sisi lain komunitas biota di daerah berbatu jauh lebih kompleks dari daerah lain karena bervariasinya relung ekologis yang disediakan oleh genangan air, celah-celah batu permukaan batu dan hubungan mereka yang bervariasi terhadap cahaya, gerakan air, perubahan suhu dan faktor lainnya (Dahuri et al. 2001).

Tabel 1 Hasil penilaian analisis kesesuaian lahan kawasan wisata alam pantai panjang di Kota Bengkulu

\begin{tabular}{clcccc}
\hline No & Parameter Kesesuaian Lahan & Kondisi Pantai Panjang & Bobot & Skor & IKW \\
\hline 1 & Kedalaman (m)* & 0.894 & 0.125 & 3 & 0.375 \\
2 & Tipe pantai & Berpasir & 0.200 & 3 & 0.6 \\
3 & Lebar pantai (m) & 57.862 & 0.200 & 3 & 0.6 \\
4 & Material dasar perairan* & Pasir & 0.170 & 3 & 0.51 \\
5 & Kecepatan arus (m/s)* & 59.6 & 0.080 & 0 & 0 \\
6 & Kemiringan (derajat)* & $3-8$ & 0.080 & 3 & 0.24 \\
7 & Kecerahan perairan (\%)* & 45.506 & 0.125 & 1 & 0.125 \\
8 & Penutupan lahan pantai & Lahan terbuka, cemara & 0.010 & 3 & 0.03 \\
9 & Biota berbahaya & Tidak ada & 0.005 & 3 & 0.015 \\
10 & Ketersediaan air tawar (km) & 0.095 & 0.005 & 2 & 0.01 \\
\hline
\end{tabular}

Keterangan: Tanda * sumber data dari Apriliansyah et all. (2018)

\subsubsection{Lebar pantai}

Lebar pantai merupakan salah satu parameter penting dalam melakukan aktivitas wisata pantai karena dengan kondisi lebar pantai yang lebar akan membuat pengunjung leluasa melakukan berbagai macam kegiatan wisata pantai. Lebar Pantai Panjang di Kota Bengkulu yaitu 57.862 meter. Menurut Yulianda (2007), lebar pantai yang sangat sesuai untuk kegiatan wisata pantai adalah lebih dari 15 meter.

\subsubsection{Material dasar perairan}

Pantai Panjang Kota Bengkulu termasuk ke dalam jenis pantai berpasir putih dengan sedikit pecahan karang (didominasi oleh pasir). Pasir yang berwarna putih tidak mudah menyerap panas matahari, sehingga tidak menyebabkan rasa panas di kaki. Menurut Hardjowigeno dan Widiatmaka (2007) untuk kegiatan wisata pantai akan sangat baik jika suatu pantai yang didominasi oleh substrat pasir atau dengan kata lain merupakan pantai yang berpasir. Apabila dibandingkan dengan pantai yang berbatu atau pantai yang didominasi oleh pecahan karang, karena dengan material dasar perairan yang didominasi oleh karang atau batu dapat mengganggu kenyamanan para pengunjung.

\subsubsection{Kecepatan arus}

Pantai Panjang Kota Bengkulu memiliki kecepatan arus $0.596 \mathrm{~m} /$ det. Jika dilihat pada matriks kesesuaian lahan untuk wisata pantai kategori rekreasi menurut Yulianda (2019) dapat dikatakan bahwa kecepatan arus tersebut sangat tidak sesuai 
untuk aktivitas berenang karena memiliki kecepatan arus kategori $\mathrm{N}$ dengan kecepatan $>0.51 \mathrm{~m} / \mathrm{dt}$.

\subsubsection{Kemiringan pantai}

Pengukuran kemiringan pantai dilakukan untuk mengetahui jenis pantai dan penyebab terbentuknya pantai. Pantai Kota Bengkulu memiliki jenis pantai yang datar kerena memiliki kemiringan pantai berkisar antara $3-8$ derajat. Hal ini menunjukkan bahwa kemiringan pantai panjang sangat sesuai untuk aktivitas wisata $(<100)$ (Yulianda 2019).

\subsubsection{Kecerahan perairan}

Kecerahan perairan menunjukkan kemampuan cahaya untuk menembus lapisan air pada kedalaman tertentu. Kecerahan perairan erat kaitannya dengan keamanan dan kenyamanan pengunjung, karena dapat mempengaruhi penglihatan di dalam air. Kawasan wisata alam Pantai Panjang Kota Bengkulu memiliki kecerahan perairan 45.506 persen. Menurut Effendi (2003), nilai kecerahan perairan sangat dipengaruhi oleh keadaan cuaca, kekeruhan dan padatan tersuspensi. Kekeruhan disebabkan oleh adanya bahan organik dan anorganik yang tersuspensi dan terlarut. Kondisi air keruh yang diakibatkan padatan tersuspensi akan mempengaruhi kemampuan penetrasi sinar matahari.

\subsubsection{Penutupan lahan pantai}

Kondisi penutupan kawasan pantai panjang didominasi oleh lahan terbuka dan sebagian pohon cemara. Penutupan lahan pantai menurut Yulianda (2019), sangat sesuai untuk aktivitas ekowisata pantai. Dalam hubungan dengan pengembangan ekowisata pantai maka diperlukan pengelolaan pada kawasan hutan pantai. Pengelolaan penutupan lahan pantai bertujuan untuk meningkatkan daya tarik ekowisata di kawasan pantai.

\subsubsection{Biota berbahaya}

Kondisi pantai panjang kota Bengkulu pada parameter ini termasuk kategori snagat sesuai menurut Yulianda (2007), karena tidak ditemukan biota berbahaya. Menurut Pratesthi et al. (2016), tidak adanya biota berbahaya pada perairan pantai akan membuat aman untuk kegiatan wisata pantai, seperti, berenang, dan snorkeling.

\subsubsection{Ketersediaan air tawar}

Pantai panjang dapat dikatakan sangat sesuai untuk aktivitas wisata, karena memiliki jarak ketersediaan air tawar 0.095 kilometer. Sebagaimana menurut Yulianda (2007) pada matriks kesesuaian lahan kategori wisata pantai bahwa suatu wisata pantai dapat dikatakan sangat sesuai jika memiliki jarak ketersediaan air tawar $<0,5$ kilometer.

Hasil analisis 10 parameter kesesuaian lahan wisata Pantai Panjang di Kota Bengkulu, menunjukkan bahwa Pantai Panjang memiliki nilai indeks kesesuaian wisata (IKW) 2.505, dan tergolong sangat sesuai untuk aktivitas wisata alam pantai, kategori rekreasi pantai. Menurut Yulianda (2019) kesesuaian sumberdaya untuk wisata pantai kategori rekreasi pantai dapat dikatakan sangat sesuai jika memiliki nilai indeks kesesuaian wisata (IKW) $\geq 2.5$.

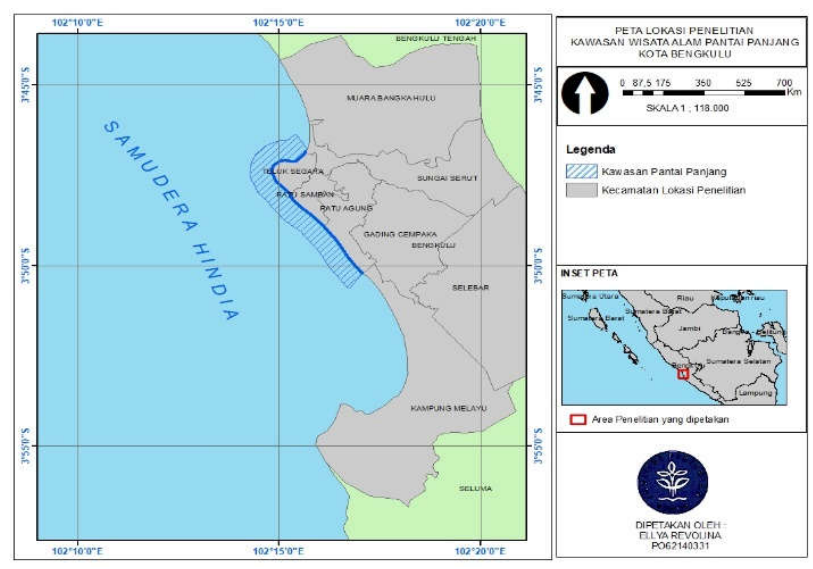

Gambar 2 Lokasi kawasan wisata alam Pantai Panjang Kota Bengkulu

\subsection{Analisis Keberlanjutan Pengelolaan Kawasan Wisata Alam Pantai Panjang \\ 3.2.1.Status Keberlanjutan pada Dimensi Ekologi}

Status keberlanjutan pengelolaan kawasan wisata alam Pantai Panjang pada dimensi ekologi menunjukan nilai 52,02 atau cukup berkelanjutan pada skala 51-75 (Abdullah et al., 2011). Atributatribut yang ada pada dimensi ekologi ini masih harus ditingkatkan lagi untuk mendukung keberlanjutan pengelolaan kawasan wisata alam Pantai Panjang sehingga statusnya terus meningkat menjadi lebih baik. Terdapat 5 (lima) atribut pada dimensi ekologi yang mempengaruhi keberlanjutan kawasan wisata alam Pantai Panjang Kota Bengkulu, yaitu: 1) Ketersediaan air bersih (Tesfamichael and Pitcher, 2006), 2) Penanganan sampah , 3) Kesesuaian lahan wisata (BSNI, 2014), 4) Terpeliharanya keberadaan dan kualitas ODTW utama (BSNI, 2014), 5) Terpeliharanya lansekap alami (BSNI, 2014). Pada penelitian ini, untuk mengetahui atribut pengungkit (leverage attributes) mana yang paling sensitif mempengaruhi keberlanjutan pengelolaan kawasan wisata alam Pantai Panjang Kota Bengkulu pada setiap dimensi digunakan analisis pareto. Analisis pareto dapat digunakan untuk mengidentifikasi faktor pengungkit utama dari sejumlah permasalahan yang terjadi atau kebutuhan yang diinginkan (Ahmed \& Ahmad, 2011).

Berdasarkan hasil analisis laverage yang dinyatakan dalam bentuk nilai Root Mean Square (RMS), dari kelima atribut dimensi ekologi terdapat 2 (dua) atribut sensitif yang menjadi atribut pengungkit dan memerlukan intervensi kebijakan karena perubahannya berpengaruh sensitif terhadap nilai indeks keberlanjutan pada dimensi ekologi, yaitu: ketersediaan air bersih dan keterpeliharaan landscape alami (Gambar 3). Kedua atribut tersebut memerlukan intervensi atau penanganan dari 
Pemerintah Daerah agar keberlanjutan pada dimensi ekologi dapat menjadi lebih baik. Kesimpulan ini diperkuat dengan hasil analisis pareto seperti pada Gambar 4.

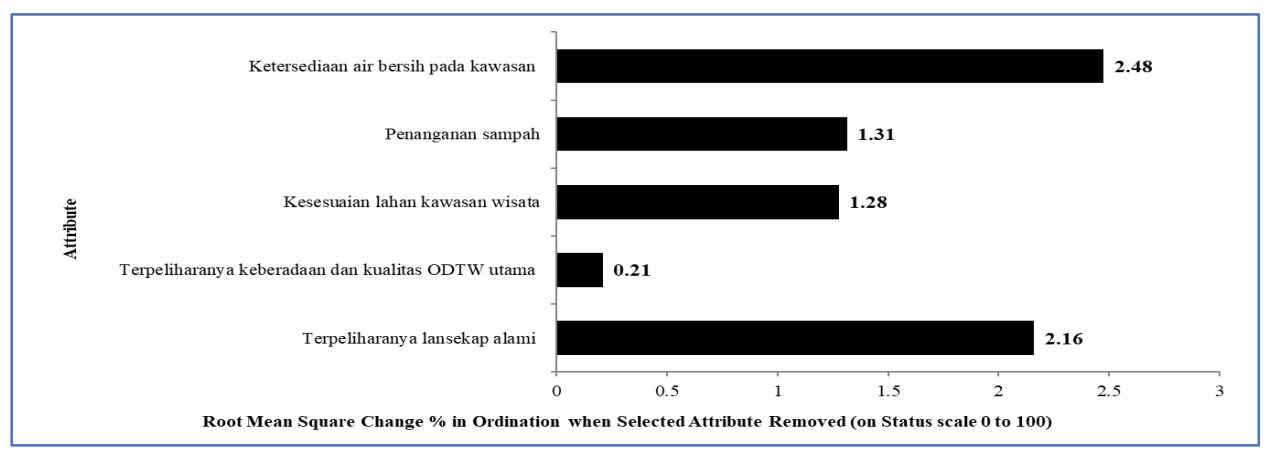

Gambar 3 Hasil analisis leverage atribut keberlanjutan dimensi ekologi

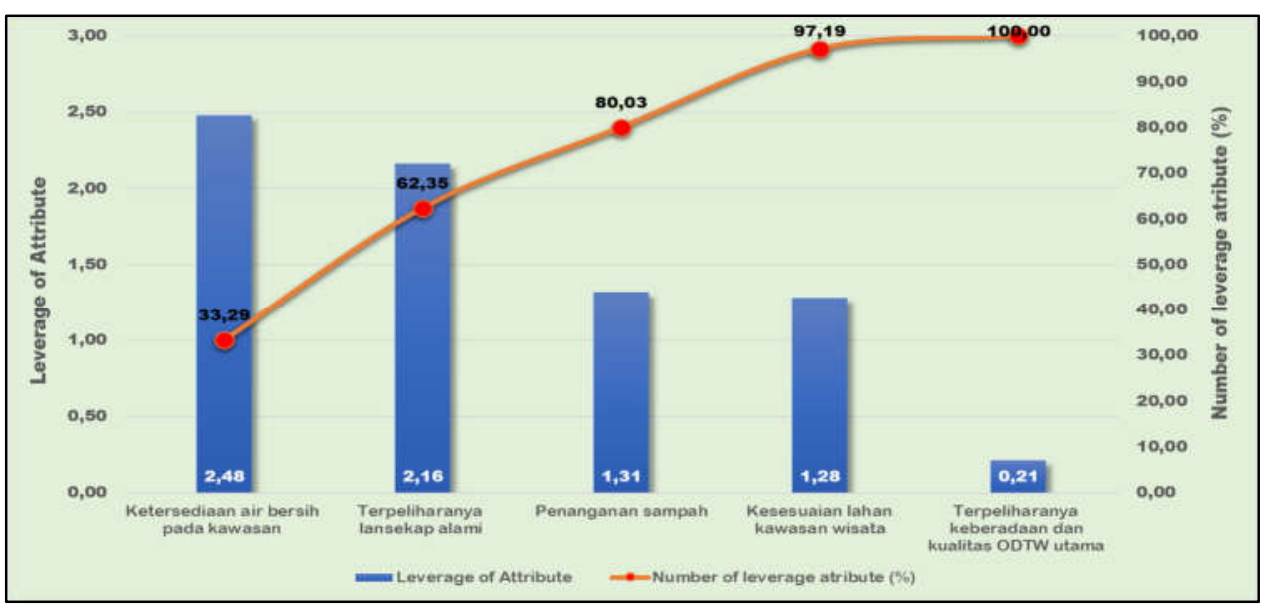

Gambar 4 Analisis pareto penentuan atribut sensitif pada dimensi ekologi

Ketersediaan air bersih merupakan salah satu atribut yang sensitif pada dimensi ekologi di kawasan wisata alam Pantai Panjang. Jika suatu kawasan memiliki ketersediaan air bersih yang cukup, maka akan berpengaruh terhadap daya tarik wisatawan untuk mengunjungi kawasan tersebut. Jauhnya jarak atau ketiadaan air bersih yang merupakan kebutuhan utama para wisatawan akan menjadi faktor yang dapat menurunkan kualitas dari sebuah kawasan wisata. Di samping ketersediaan air bersih, terpeliharanya landscape alami kawasan Pantai Panjang juga menjadi daya tarik utama yang mampu mempengaruhi preferensi para wisatawan untuk memilih kawasan wisata alam Pantai Panjang sebagai tujuan wisatanya. Program yang dapat dilakukan oleh pengelola kawasan yaitu menyediakan infrastruktur penyediaan air bersih dan mempermudah akses wisatawan terhadap sumber air bersih di dalam kawasan wisata secara merata sehingga dapat memenuhi kebutuhan para wisatawan. Disamping itu, perlu dibuat kebijakan oleh pengelola terkait larangan menebang pepohonan dan merubah kealamian landscape kawasan menjadi bentuk lain.

\subsubsection{Status Keberlanjutan pada Dimensi Ekonomi}

Secara umum, kegiatan perekonomian masyarakat di sekitar kawasan wisata alam Pantai
Panjang Kota Bengkulu masih bergantung pada sektor perikanan dan perdagangan. Masyarakat yang berada di sekitar kawasan umumnya berprofesi sebagai nelayan dan pedagang kecil. Sebagai nelayan, yang dalam operasional kerjanya masih menggunakan perahu dan alat tangkap sederhana, jumlah tangkapan ikan selama melaut tidak dapat dipastikan, sehingga menyebabkan kegiatan yang mereka lakukan tidak jarang hanya dapat memenuhi kebutuhan hidup mereka secara subsisten. Hal inilah yang menyebabkan kondisi perekonomian masyarakat sekitar kawasan relatif masih belum begitu baik. Dengan adanya kondisi tersebut, masyarakat mulai mencari alternatif pendapatan tambahan, diantaranya dengan memanfaatkan keberadaan kawasan wisata alam Pantai Panjang untuk menjual makanan atau minuman. Nilai indeks keberlanjutan dimensi ekonomi, kawasan wisata alam Pantai Panjang Kota Bengkulu sebesar 47,59 termasuk kategori Kurang Berkelanjutan. Nilai tersebut menunjukan bahwa atribut-atribut ekonomi pada dimensi ini kurang mendukung untuk menjaga keberlanjutan pengelolaan kawasan wisata alam Pantai Panjang di Kota Bengkulu.

Pada dimensi ini, terdapat 5 (lima) atribut ekonomi yang mempengaruhi status keberlanjutan pengelolaan kawasan wisata alam Pantai Panjang 
Kota Bengkulu, yaitu: 1) Potensi pasar kawasan wisata (Tesfamichael and Pitcher, 2006), 2) Tingkat kunjungan wisatawan (Tesfamichael and Pitcher, 2006), 3) Jumlah masyarakat yang memanfaatkan keberadaan kawasan wisata (modifikasi Nikijuluw, 2002), 4) Rata-rata tambahan pendapatan masyarakat dari kawasan wisata (Osmaleli, 2014), dan 5) Kontribusi kawasan wisata terhadap PAD (Nikijuluw, 2002). Berdasarkan hasil analisis leverage, terdapat 2 (dua) atribut pengungkit yang sensitif pengaruhnya terhadap keberlanjutan pengelolaan kawasan wisata alam Pantai Panjang Kota Bengkulu pada dimensi ekonomi, yaitu: (1) Potensi pasar kawasan wisata, dan (2) Kontribusi kawasan wisata terhadap Pendapatan Asli Daerah (PAD). Kedua atribut sensitif tersebut harus mendapatkan intervensi kebijakan yang tepat sehingga mendukung terhadap keberlanjutan pengelolaan kawasan wisata alam Pantai Panjang Kota Bengkulu di masa yang akan datang. Hasil analisis leverage pada dimensi ekonomi dapat dilihat pada Gambar 5 yang diperkuat hasil analisis pareto pada Gambar 6.

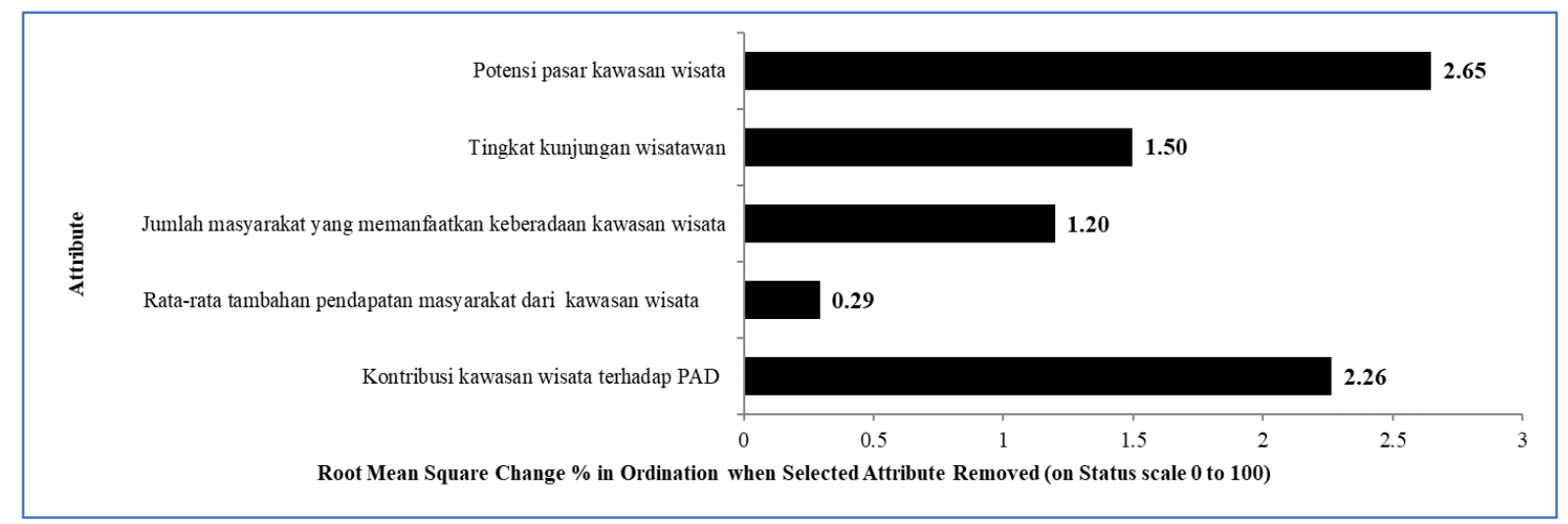

Gambar 5 Hasil analisis leverage atribut keberlanjutan dimensi ekonomi

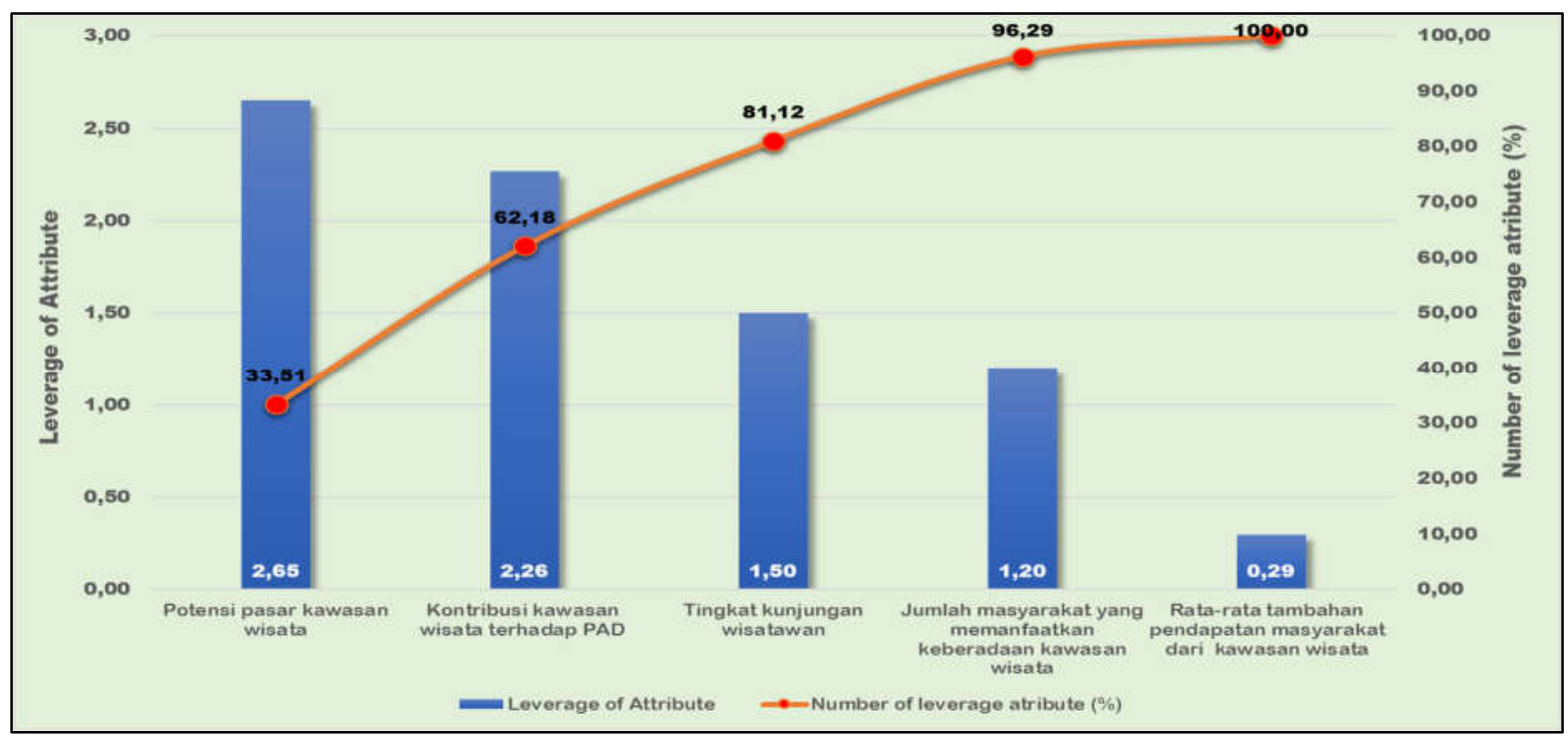

Gambar 6 Analisis pareto penentuan atribut sensitif pada dimensi ekonomi

Berdasarkan Gambar 5 dan 6 dapat dijelaskan sebagai berikut: 1) Potensi pasar kawasan wisata, harus menjadi perhatian pihak pengelola dan pemerintah daerah, sebab melalui analisa potensi pasar, perencanaan pengelolaan dapat dilakukan dengan maksimal. Melalui pengenalan potensi pasar, maka segmentasi permintaan dan penawaran kawasan wisata dapat lebih mudah untuk direncanakan, dapat memberikan pengaruh terhadap jumlah wisatawan dan menjadi sumber penerimaan bagi kawasan dari seluruh rangkaian aktifitas kunjungan wisatawan. Saat ini kondisi dan keberadaan kawasan wisata belum tersosialisasi dengan baik secara nasional. Kondisi ini menyebabkan pihak pengelola belum dapat memetakan potensi pasar dengan baik, sehingga arah dan perencanaan kawasan wisata dilakukan secara tidak tepat. 2) Kontribusi kawasan wisata terhadap pendapatan asli daerah (PAD) merupakan atribut sensitif dalam pengelolaan kawasan wisata alam Pantai Panjang Kota Bengkulu. Saat ini kontribusi sektor jasa khususnya pariwisata kota Bengkulu masih dibawah 10\%. Oleh karena itu, diperlukan intervensi Pemerintah Daerah untuk meningkatkan kontribusi kawasan melalui kebijakan fiskal maupun non fiskal agar kontribusinya terhadap Pendapatan 
Asli Daerah (PAD) menjadi optimal yang pada akhirnya dapat memberikan kontribusi yang nyata sebagai salah satu sumber bagi APBD Bengkulu. Program yang dapat dilakukan oleh pengelola kawasan adalah meningkatkan promosi keberadaan kawasan wisata alam Pantai Panjang Kota Bengkulu secara nasional dan internasional serta memetakan potensi pasar kawasan wisata tersebut. Disamping itu pihak pengelola harus meningkatkan layanan dan antraksi wisata beserta infrastrukturnya sehingga meningkatkan daya tarik wisata yang pada akhirnya akan meningkatkan PAD Kota Bengkulu.

\subsubsection{Status Keberlanjutan pada Dimensi Sosial}

Hasil analisis status keberlanjutan pengelolaan kawasan wisata alam Pantai Panjang Kota Bengkulu, dimensi sosial menunjukan indeks keberlanjutan sebesar 42,74 dan termasuk kategori Kurang Berkelanjutan. Pada dimensi ini, terdapat 6 (enam) atribut yang memiliki pengaruh terhadap status keberlanjutan kawasan wisata alam Pantai Panjang Kota Bengkulu, yaitu: 1) Ketersediaan prasarana pendukung kegiatan wisata (Tesfamichael and Pitcher, 2006), 2) Ketersediaan transportasi wisata (Tesfamichael and Pitcher, 2006), 3) Penyerapan tenaga kerja (Tesfamichael and Pitcher, 2006), 4) Keamanan lingkungan pada objek wisata (Tesfamichael and Pitcher, 2006), 5) Potensi konflik dan pemanfaatan (Nikijuluw, 2002), 6) Pengetahuan pelestarian obyek wisata (Modifikasi Tesfamichael and Pitcher, 2006), dan 7) Tingkat pendidikan penduduk sekitar kawasan (Santoso, 2012).

Hasil analisis leverage pada dimensi sosial sebagaimana Gambar 7 menunjukan bahwa dari 7 (tujuh) atribut yang ada, terdapat 3 (tiga) atribut yang sensitif pengaruhnya terhadap keberlanjutan pengelolaan kawasan wisata alam Pantai Panjang Kota Bengkulu, Atribut-atribut yang dimaksud adalah: (1) ketersediaan transportasi wisata, (2), Pengetahuan pelestarian objek wisata dan (3) Keamanan lingkungan pada objek wisata. Kesimpulan ini diperkuat dengan hasil analisis pareto seperti pada Gambar 8.

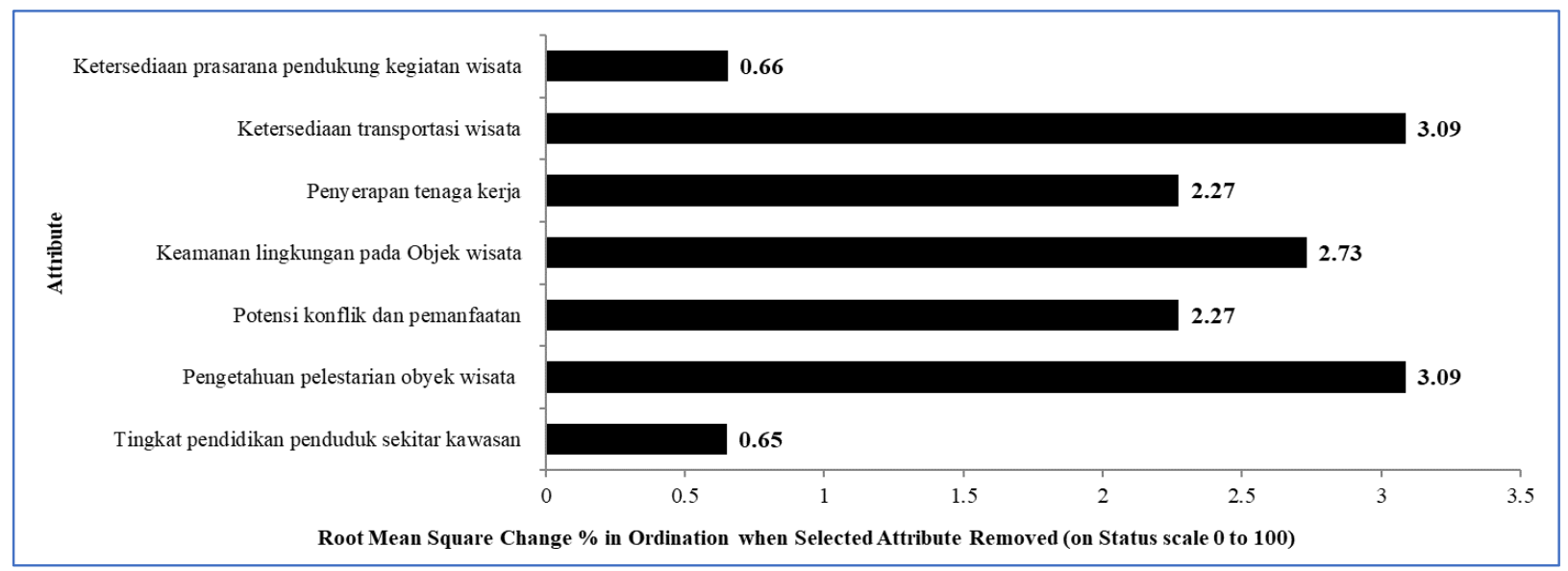

Gambar 7 Hasil analisis leverage atribut keberlanjutan dimensi sosial

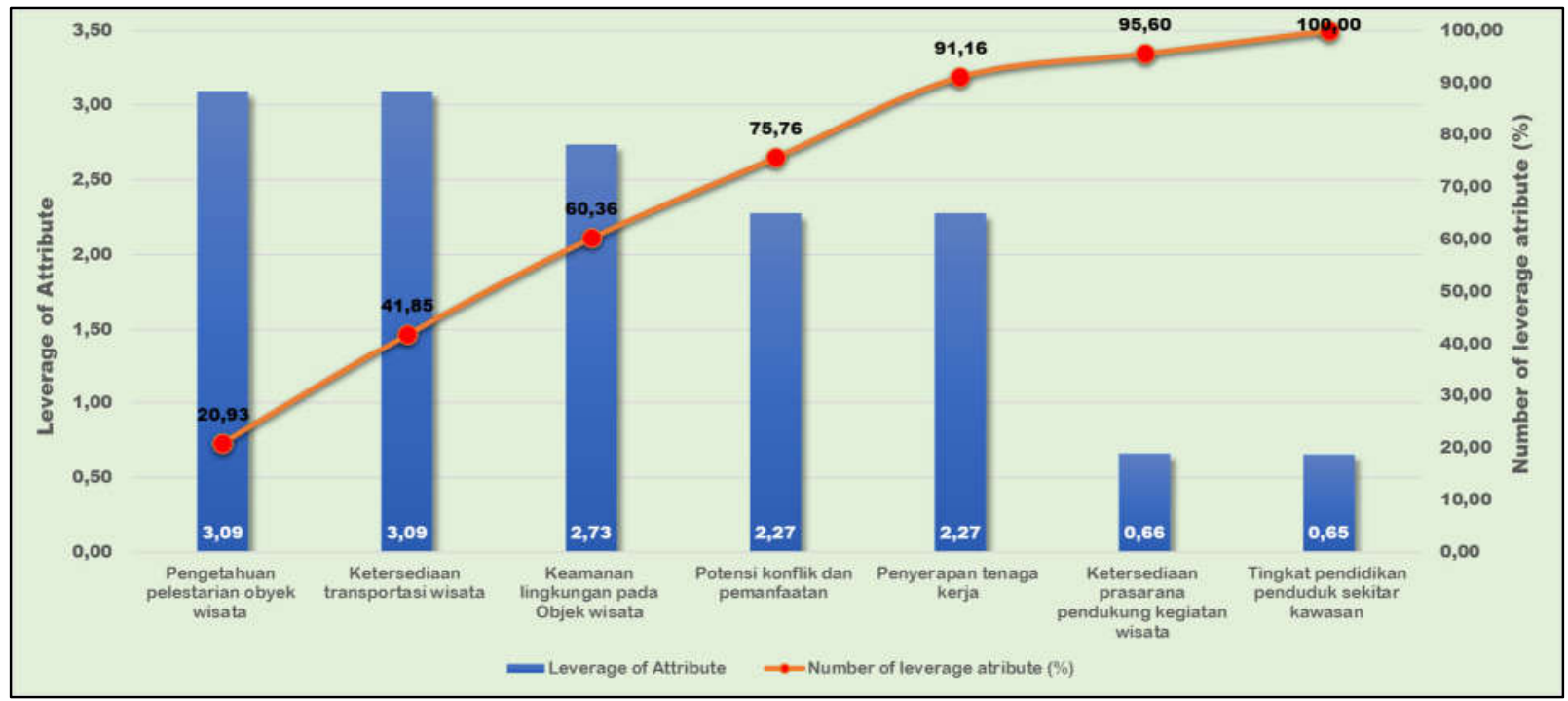

Gambar 8 Analisis pareto penentuan atribut sensitif pada dimensi kelembagaan 
Intervensi kebijakan yang dapat dilakukan oleh pihak pengelola kawasan adalah berkoordinasi dengan instansi terkait dalam mengatur dan menyediakan transportasi dari dan menuju kawasan wisata dengan kapasitas yang memadai. Disamping itu, program pembinaan secara intensif dan berkala kepada masyarakat khususnya masyarakat yang berada di sekitar kawasan harus dilakukan untuk menumbuhkan rasa kepedulian akan kelestarian, kebersihan dan keamanan kawasan wisata alam Pantai Panjang Kota Bengkulu.

\subsubsection{Status Keberlanjutan pada Dimensi Kelembagaan}

Aspek kelembagaan merupakan aspek yang sangat penting dalam mendukung keberlanjutan suatu sumberdaya. Jika suatu sumberdaya mengalami kerusakan maka patut diduga aspek kelembagaannya mengalami masalah (Kuvaini, 2019). Pada dimensi kelembagaan, nilai indeks keberlanjutan pengelolaan kawasan wisata alam Pantai Panjang adalah 40.79. Hal ini mengindikasikan status keberlanjutan masuk pada kategori kurang berkelanjutan. Diantara ke empat dimensi keberlanjutan, dimensi kelembagaan merupakan dimensi yang memiliki nilai indeks keberlanjutan paling rendah.

Pada dimensi kelembagaan, terdapat 9 (sembilan) atribut yang berpengaruh terhadap keberlanjutan pengelolaan kawasan wisata alam Pantai Panjang Kota Bengkulu, yaitu: 1) Peran swasta dalam pengelolaan (Tesfamichael and Pitcher, 2006), 2) Penegakan hukum (Nikijuluw, 2002), 3) Pola kemitraan pengelolaan (Nikijuluw, 2002), 4) Kesesuaian pengembangan kawasan terhadap RTRW dan RIPD (Modifikasi Nikijuluw, 2002), 5) Pelibatan lembaga masyarakat lokal dalam pengelolaan
(Osmaleli, 2014), 6) Partisipasi masyarakat lokal dalam pengelolaan (Osmaleli, 2014), 7) Pelaksanaan, pengawasan dan promosi sumberdaya alam (Tesfamichael and Pitcher, 2006), 8) Ketersediaan peraturan pengelolaan kawasan pantai (Santoso, 2012), dan 9) Status pengelola kawasan (Santoso, 2012).

Berdasarkan analisis laverage terhadap atributatribut pada dimensi kelembagaan, terdapat 3 (tiga) atribut pengungkit yang memiliki pengaruh sensitif terhadap status keberlanjutan pengelolaan kawasan wisata alam Pantai Panjang Kota Bengkulu, yaitu: (1) Partisipasi masyarakat lokal dalam pengelolaan, dan (2) Pola kemitraan pengelolaan dan (3) Pelibatan lembaga masyarakat lokal dalam pengelolaan. Hasil analisis laverage dan analisis Pareto pada dimensi kelembagaan dapat dilihat pada Gambar 9 dan Gambar 10. Ketiga atribut yang sensitif pada dimensi kelembagaan ini harus mendapatkan perhatian yang besar dalam implementasi kebijakan pengelolaan kawasan wisata alam Pantai Panjang Kota Bengkulu, mengingat atribut tersebut sangat berpengaruh dalam mendukung keberlanjutan pengelolaan kawasan wisata alam Panjang Panjang Kota Bengkulu di masa yang akan datang.

Intervensi kebijakan yang dapat diterapkan oleh pihak pengelola, yaitu meningkatkan partisipasi masyarakat dalam pengelolaan kawasan wisata dalam bentuk membuat lembaga pengelola yang baru dengan melibatkan lembaga yang ada di masyarakat secara formal, serta membangun jejaring kerjasama kemitraan dengan pihak swasta atau pemangku kepentingan yang lain. Melalui keterlibatan berbagai pemangku kepentingan ini maka pengelolaan kawasan wisata alam Pantai Panjang Kota Bengkulu akan lebih baik dan berkelanjutan.

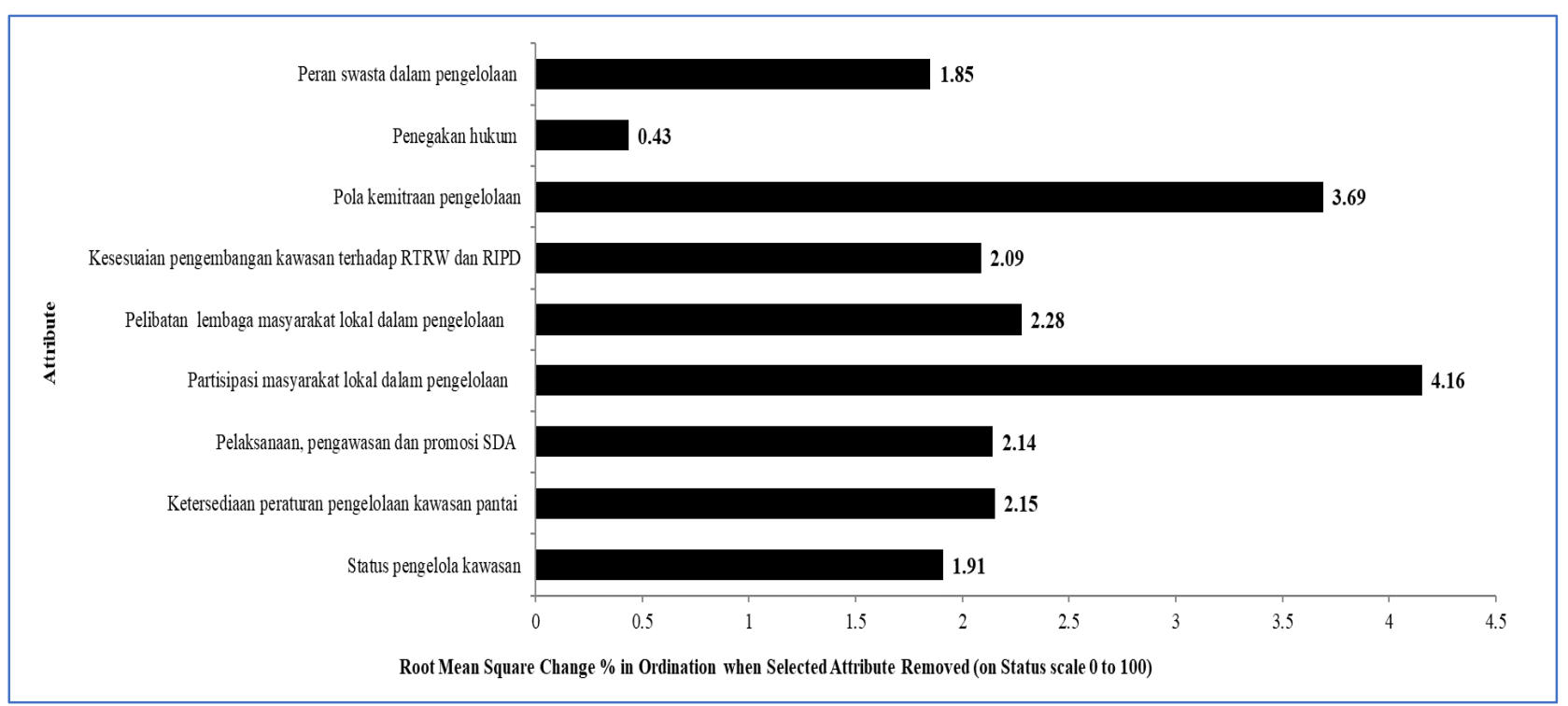

Gambar 9 Hasil analisis leverage atribut keberlanjutan dimensi kelembagaan 


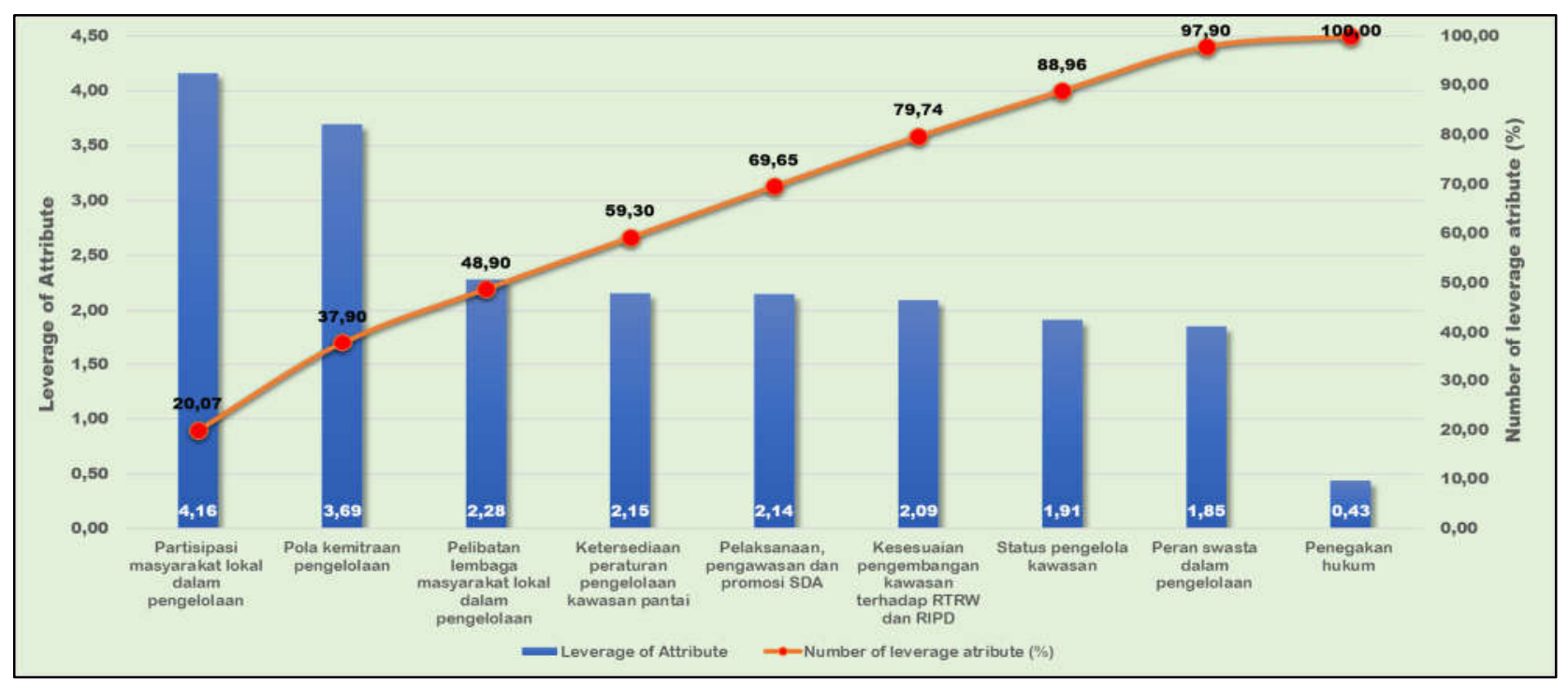

Gambar 10 Analisa Pareto penentuan Atribut Sensitif pada Dimensi Kelembagaan

Hasil penilaian status keberlanjutan pengelolaan kawasan wisata alam Pantai Panjang pada dimensi ekologi, ekonomi, sosial dan kelembagaan yang telah diuraikan sebelumnya secara ringkas dapat dilihat pada Tabel 2, serta dapat disajikan dalam bentuk diagram layang keberlanjutan (Fauzi 2019) (Gambar 11).

Berdasarkan penilaian analisis status keberlanjutan pengelolaan kawasan wisata alam Pantai Panjang secara umum diketahui bahwa tingkat keberlanjutan pengelolaan masih belum baik; dari 4 dimensi keberlanjutan, hanya 1 dimensi saja yang berstatus cukup berkelanjutan, yaitu dimensi ekologi, sedangkan dimensi lainnya (ekonomi, sosial dan kelembagaan) termasuk kategori kurang berkelanjutan. Hal ini merujuk pada Fauzi \& Anna (2002) bahwa nilai keberlanjutan dinyatakan tidak berkelanjutan bilamana memiliki indeks sebesar (024.99), kurang berkelanjutan (25.00-49.99), cukup berkelanjutan (50.00 - 74.99) dan berkelanjutan pada nilai (75.00-100).

Menurut Andronicus et al. (2016), atribut sensitif yang dihasilkan pada setiap dimensi secara kuantitatif tidaklah sama, karena sangat bergantung pada penilaian riil di lapangan. Oleh karena itu, program riil untuk memperbaiki seluruh atribut pengungkit semua dimensi (Tabel 3) harus dilakukan dengan cara intervensi kebijakan secara tepat agar tingkat keberlanjutan pengelolaan kawasan wisata alam Pantai Panjang Kota Bengkulu menjadi lebih baik. Atribut-atribut pengungkit tersebut harus menjadi dasar dalam melakukan perencanaan pengelolaan kawasan wisata alam Pantai Panjang di masa yang akan datang.

Tabel 2 Status keberlanjutan pengelolaan kawasan wisata alam Pantai Panjang pada setiap dimensi

\begin{tabular}{clcl}
\hline No & \multicolumn{1}{c}{ Dimensi } & Indeks & Status Keberlanjutan \\
\hline 1. & Ekologi & 52.02 & Cukup berkelanjutan \\
2. & Ekonomi & 47.59 & Kurang berkelanjutan \\
3. & Sosial & 42.74 & Kurang berkelanjutan \\
4. & Kelembagaan & 40.79 & Kurang berkelanjutan \\
\hline
\end{tabular}

Tabel 3 Atribut-atribut sensitif pengelolaan kawasan wisata alam Pantai Panjang Kota Bengkulu

\begin{tabular}{clll}
\hline No & Dimensi & & \multicolumn{1}{c}{ Atribut Sensitif } \\
\hline 1. & Ekologi & 1. & Ketersediaan air bersih \\
& & 2. & Terpeliharanya lansekap alami \\
2. & Ekonomi & 1. & Potensi pasar kawasan wisata \\
& & 2. & Kontribusi kawasan terhadap PAD \\
3. & Sosial & 1. & Ketersediaan transportasi wisata \\
& & 2. & Pengetahuan pelestarian objek wisata \\
& & 3. & Keamanan lingkungan objek wisata \\
4. & Kelembagaan & 1. & Pola kemitraan pengelolaan \\
& & 2. & Partisipasi masyarakat lokal dalam pengelolaan \\
& & 3. & Pelibatan lembaga masyarakat lokal dalam pengelolaan \\
\hline
\end{tabular}




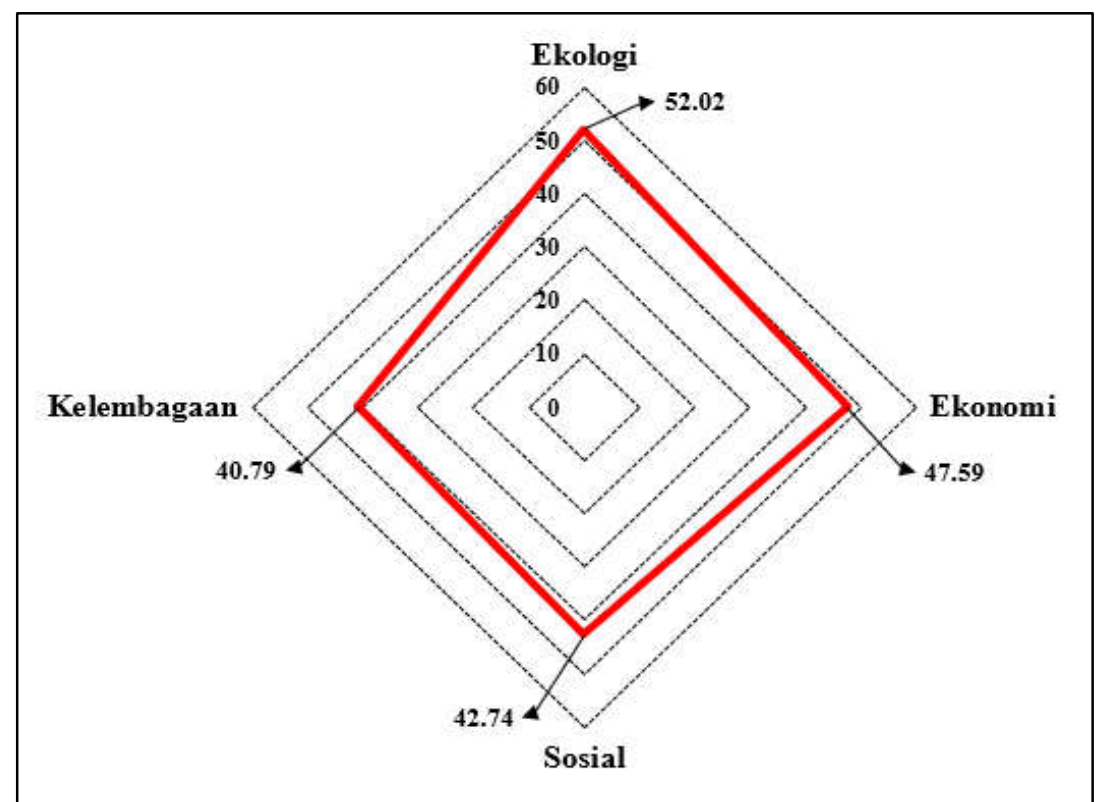

Gambar 11 Diagram layang keberlanjutan pengelolaan Pantai Panjang Kota Bengkulu

\subsection{Validitas Hasil Analisis Multidimensional Scalling (MDS)}

Validitas analisis Multidimensional Scalling (MDS) ditunjukkan dengan hasil analisis Monte Carlo (Tabel 4) dan nilai goodness of fit yaitu nilai stress dan koefisien determinasi (R2) pada tingkat kepercayaan 95\% (Tabel 5). Perbedaan indeks hasil analisis Multidimensional Scalling (MDS) dengan indeks hasil analisis Monte Carlo yang kecil mengindikasikan bahwa dalam proses analisis terjadinya kesalahan pembuatan skor relatif kecil, variasi pemberian skor akibat perbedaan opini relatif kecil, proses analisis yang berulang-ulang stabil, dan kesalahan pemasukan data ataupun data hilang dapat dihindari. Ini berarti bahwa validitas analisis MDS yang digunakan cukup baik untuk menilai keberlanjutan pengelolaan kawasan wisata alam Pantai Panjang Kota Bengkulu.

Tabel 4 Perbandingan hasil indeks keberlanjutan MDS dan hasil analisis Monte Carlo

\begin{tabular}{clccc}
\hline No. & \multicolumn{1}{c}{ Dimensi } & Hasil MDS & Hasil Monte Carlo & Selisih \\
\hline 1. & Ekologi & 52.02 & 51.91 & 0.11 \\
2. & Ekonomi & 47.59 & 47.32 & 0.27 \\
3. & Sosial & 42.74 & 43.24 & 0.50 \\
4. & Kelembagaan & 40.79 & 41.43 & 0.64 \\
\hline
\end{tabular}

Tabel 5 Nilai Goodness Of Fit (Nilai Stress dan Koefisien Determinasi $\left(\mathrm{R}^{2}\right)$

\begin{tabular}{|c|c|c|c|}
\hline No. & Dimensi & Nilai stress & Nilai $R^{2}$ \\
\hline 1. & Ekologi & 0.169 & 0.935 \\
\hline 2. & Ekonomi & 0.168 & 0.937 \\
\hline 3. & Sosial & 0.152 & 0.946 \\
\hline 4. & Kelembagaan & 0.143 & 0.950 \\
\hline
\end{tabular}

\section{Kesimpulan}

Kawasan wisata alam Pantai Panjang Kota Bengkulu, secara umum sangat sesuai untuk aktivitas wisata alam pantai kategori rekreasi pantai, karena memiliki nilai indeks kesesuaian (IKW) 2.502 pada skala nilai IKW $\geq 2.5$. Secara umum status keberlanjutan pengelolaan kawasan wisata alam Pantai Panjang termasuk kategori kurang berkelanjutan. Pada dimensi ekologi statusnya cukup berkelanjutan (MDS 52.02), dimensi ekonomi (MDS 47.59), dimensi sosial (MDS 42.74) dan dimensi kelembagaan (MDS 40.79), ketiganya memiliki indeks kurang berkelanjutan. Adapun atribut-atribut sensitif yang berpengaruh pada pengelolaan kawasan wisata alam Pantai Panjang Kota Bengkulu yaitu: (1) Ketersediaan air tawar, (2) Terpeliharanya lansekap alami, (3) Potensi pasar kawasan wisata, (4) Kontribusi kawasan terhadap PAD, (5) Ketersediaan transportasi wisata, (6) Pengetahuan pelestarian objek wisata, (7) Keamanan lingkungan objek wisata, (8) Pola kemitraan pengelolaan, (9) Partisipasi masyarakat lokal terhadap pengelolaan, dan (10) Pelibatan lembaga masyarakat lokal dalam pengelolaan. Ditinjau dari berbagai dimensi yang ada, 
terlihat bahwa kondisi kelembagaan yang ada saat ini belum mampu untuk mengelola kawasan wisata alam Pantai Panjang secara berkelanjutan, sehingga kawasan wisata ini memerlukan sebuah kelembagaan baru yang mampu melibatkan berbagai unsur pemangku kepentingan secara terintegrasi, serta berorientasi kepada keberlanjutan pengelolaan kawasan wisata alam Pantai Panjang baik pada dimensi ekologi, ekonomi, sosial dan kelembagaan, khususnya berbagai faktor yang menjadi atribut pengungkit.

\section{DAFTAR PUSTAKA}

Abdullah RM, Wisudo, Monintja, Sondita MFA. 2011. Keberlanjutan Perikanan Tangkap di Kota Ternate pada Dimensi Ekologi. Buletin PSP. 19(1):113-126.

Ahmed M, Ahmad N. 2011. An Application of Pareto Analysis and Cause-and-Effect Diagram (CED) for Minimizing Rejection of Raw Materials in Lamp Production Process. Management Science and Engineering. 5(3):87-95.

Andronicus, Yulianda F, Fahrudin A. 2016. Kajian Keberlanjutan Pengelolaan Ekowisata Berbasis Daerah Perlindungan Laut (Dpl) Di Pesisir Desa Bahoi, Minahasa Utara, Sulawesi Utara. Journal of Engineering and Management in Industrial System, 4 (1): $1-10$

Angelina M, Evelina LW. 2014. Bingkai Pemberitaan Reklamasi Teluk Benoa Bali. Humaniora 5 (2): 803815

Apriliansyah, Purnama D, Johan Y, Renta PP. 2018. Analisis Parameter Oseanografi dan Lingkungan Ekowisata Pantai di Pantai Panjang Kota Bengkulu. Jurnal Enggano. 3(2):211-227.

[BSNI] Badan Standarisasi Nasional Indonesia. 2014. Standarisasi Pengelolaan Pariwisata Alam SNI 8013:2014. Jakarta (ID): Badan Standardisasi Nasional.

Dahuri R. 2003. Keanekaragaman Hayati Laut Aset Pembangunan Berkelanjutan Indonesia. Jakarta (ID): PT Gramedia Pustaka Utama

Fauzi A, Anna S. 2002. Evaluasi Status Keberlanjutan Pembangunan Perikanan: Aplikasi Pendekatan Rapfish (Studi Kasus Perairan Pesisir DKI Jakarta). Jurnal Pesisir dan Lautan. 4(3):43-55.

Fauzi A. 2019. Teknik Analisis Keberlanjutan. Jakarta (ID): Gramedia Pustaka Utama.
Hardjowigeno S, Widiatmaka. 2007. Evaluasi Kesesuaian lahan dan Perencanaan Tata Guna Lahan. Yogyakarta (ID): Gadjah Mada University Press.

Kuvaini A., Hidayat A., Kusmana C., \& Basuni S. 2019. Teknik penilaian multidimensi untuk mengevaluasi keberlanjutan pengelolaan hutan mangrove di Pulau Kangean Provinsi Jawa Timur. Jurnal Wilayah dan Lingkungan. 7(3): 137-152.

Laksono AN, Mussadun. 2014. Dampak Aktivitas Ekowisata di Pulau Karimunjawa Berdasarkan Persepsi Masyarakat. Jurnal Teknik Perencanaan Wilayah Kota 3 (2): 262 - 273

Nikijuluw V. 2002. Rezim Pengelolaan Sumberdaya Perikanan. Jakarta (ID): PT. Pustaka Cidesindo.

Osmaleli. 2014. Analisis Ekonomi dan Kebijakan Pengelolaan Ekosistem Mangrove Berkelanjutan di Desa Pabean Udik, Kabupaten Indramayu [tesis]. Bogor (ID): Institut Pertanian Bogor.

[PERDA] Peraturan Daerah. 2012. Peraturan Daerah Kota Bengkulu Nomor 14 Tahun 2012 tentang Rencana Tata Ruang Wilayah (RTRW) Kota Bengkulu Tahun 2012-2032. Bengkulu (ID): Sekretariat Daerah Kota Bengkulu.

[PERDA] Peraturan Daerah. 2012. Peraturan Daerah Provinsi Bengkulu Nomor 02 Tahun 2012 tentang Rencana Tata Ruang Wilayah (RTRW) Provinsi Bengkulu Tahun 2012-2032. Bengkulu (ID): Sekretariat Daerah Provinsi Bengkulu.

[PP] Peraturan Pemerintah. 2011. Peraturan Pemerintah Nomor 50 Tahun 2011 tentang Rencana Induk Pembangunan Kepariwisataan Nasional. Jakarta (ID): Sekretariat Negara RI

Santoso N. 2012. Arahan Kebijakan Dan Strategi Pengelolaan Kawasan Mangrove Berkelanjutan Di Muara Angke Daerah Khusus Ibukota Jakarta [disertasi]. Bogor

Tesfamichael D, Pitcher TJ. 2006. Multidisciplinary evaluation of the sustainability of Red Sea fisheries using Rapfish. Fisheries Research. (ID): Institut Pertanian Bogor.

Yulianda F. 2019. Ekowisata Perairan, suatu Konsep Kesesuaian dan Daya Dukung Wisata Bahari dan Wisata Air Tawar. Bogor (ID): IPB Press.

Yustishar M. 2012. Tinjauan Parameter Fisik Pantai Mangkang Kulon untuk Kesesuaian Pariwisata Pantai di Kota Semarang. Journal of Marine Research. 1(2):8-16. 